\title{
MODERNIDADE, ESPIRITUALIDADE E EDUCAÇÃO: A COMPANHIA DE JESUS DOS EXERCÍCIOS ESPIRITUAIS À RATIO STUDIORUM
}

\author{
Cézar de Alencar Arnaut de Toledo ${ }^{1}$
}

Oriomar Skalinski Junior ${ }^{2}$

Universidade Estadual de Maringá - UEM

\section{RESUMO}

Este artigo tem por objetivo demonstrar como os Exercícios Espirituais, concebidos por Inácio de Loyola, contribuíram para a composição da Ratio Studiorum fornecendo elementos conceituais que fundamentaram sua sistematização. Os Exercícios Espirituais (1539) são a base da espiritualidade dos jesuítas e a Ratio Studiorum (1599) é o documento que regulamentou a educação jesuítica. O modelo de espiritualidade da Companhia de Jesus teve como característica distintiva o foco na ideia de que o progresso espiritual é derivado do trabalho pessoal, podendo ser planejado, quantificado, avaliado, corrigido e aperfeiçoado no sentido de se alcançar objetivos previamente estabelecidos. Esta espiritualidade trouxe elementos fundamentais para o método pedagógico dos jesuítas que, entre outras coisas, determinava: a rígida organização dos horários e do conteúdo das disciplinas, a documentação do estudo, a planificação do ensino por metas, a avaliação constante, a emulação, a premiação, a ênfase na repetição, na elaboração de sínteses e no exercício. Estas características metodológicas alavancaram o sucesso da educação jesuítica, tornando-a uma das matrizes pedagógicas da Modernidade, o que contribuiu, inclusive, para a grande expansão da Companhia de Jesus nos séculos XVI e XVII.

Palavras-chave: Educação, Modernidade, Exercícios Espirituais, Ratio Studiorum, educação jesuítica.

\section{MODERNITY, SPIRITUALITY AND EDUCATION: THE SOCIETY OF JESUS FROM SPIRITUAL EXERCISES TA RATIO STUDIORUM}

\begin{abstract}
This article aims to demonstrate how the Spiritual Exercises, written by Ignatius of Loyola, contributed to the composition of the Ratio Studiorum providing conceptual elements that were the basis for its systematization. The Spiritual Exercises (1539) are the basis of the spirituality of the Jesuits and the Ratio Studiorum (1599) is the document that regulated the Jesuit education. The model of spirituality of the Society of Jesus had the distinctive feature of the focus on the idea that spiritual progress is derived from personal work and can be planned, measured, evaluated, adjusted and improved to achieve pre-established goals. This spirituality has brought key elements for the pedagogical method of the Jesuits that, among other things, determined: the rigid organization of schedules and content of disciplines, the documentation of study, the planning of teaching for goals, the constant evaluation, the emulation, the rewards, the emphasis on the repetition, on the elaboration of synthesis and on the exercise. These methodological features leveraged the success of Jesuit education, making it one of the pedagogical bases of Modernity, which also contributed to the great expansion of the Society of Jesus in the sixteenth and seventeenth centuries.
\end{abstract}

Key-words: Education, Modernity, Spiritual Exercises, Ratio Studiorum, Jesuit education. 


\section{Introdução}

Este artigo tem por objetivo demonstrar como os Exercícios Espirituais - enquanto prática essencial e fundante do modelo de espiritualidade da Companhia de Jesus contribuíram para a composição da Ratio Studiorum, fornecendo elementos conceituais que foram fundamento para sua sistematização.

$\mathrm{Na}$ primeira parte do texto são apresentados os Exercícios Espirituais enquanto instrumento apostólico, analisando-se a maneira como o manual organiza-se internamente para promover, a partir do esforço pessoal daquele que se exercita, a adesão à obra católica. Em um segundo momento, discute-se a elaboração, a estrutura e o conteúdo da Ratio Studiorum, bem como as implicações apostólicas do projeto pedagógico jesuítico. Por fim, a terceira parte deste artigo apresenta e examina os elementos que sustentam a afirmação de que o projeto educativo-apostólico da Companhia de Jesus - o de maior alcance na Modernidade - é tributário de conceitos particulares da mística-apostólica inaciana, explicitada no texto dos Exercícios Espirituais.

Ao longo da história da Igreja as Ordens Religiosas tradicionalmente possuíram distintos modos de devoção e de organização da vida espiritual, tendo cada uma características peculiares que dizem respeito à formação, estruturação e carisma ${ }^{3}$. Formaram-se assim diferentes escolas de espiritualidade que, embora guardassem diferenças marcantes entre suas ascéticas e místicas, passaram a coexistir no âmbito eclesiástico e contribuíram de modo particular para a constituição do corpo doutrinário da fé Católica ${ }^{4}$. Mesmo considerando a diversidade das características das Ordens, a Companhia de Jesus é detentora de um diferencial marcante no que diz respeito à sua doutrina espiritual, a saber, o fato de ter sido rigidamente definida e codificada por Inácio de Loyola (1491-1556) antes mesmo da fundação da Ordem. A espiritualidade jesuítica é, portanto, pautada na experiência pessoal de seu fundador que, ao longo de duas décadas de peregrinações, meditações e estudos sistematizou nos seus Exercícios Espirituais um modo muito específico de disciplina espiritual (DE LETURIA, 1957) ${ }^{5}$.

Sabidamente, a grande expansão e influência da Companhia de Jesus na Modernidade tiveram como pilar principal o êxito de sua pastoral educacional, alcançado, especialmente, em razão do sucesso de seu método de ensino. A Ratio Studiorum, promulgada em 1599, é o documento que metodicamente organizou a vida de estudos nos colégios da Companhia de Jesus ${ }^{6}$. Não se trata de um compêndio pedagógico, e sim, de um texto que descreve uma rígida ordenação de funções e atribuições, além de ser uma espécie de manual sobre organização e administração escolar. Em razão da relevância de seu conteúdo e da amplitude de seu alcance, a Ratio é tradicionalmente considerada uma das bases da pedagogia Moderna.

Embora aparentemente digam respeito a esferas distintas, uma vez que os Exercícios Espirituais se situam no campo da mística e a Ratio Studiorum no plano da educação, é possível verificar a existência de elementos comuns entre esses dois documentos.

\section{O modelo de espiritualidade da Companhia de Jesus: os Exercícios Espirituais}

Os Exercícios Espirituais foram concebidos por Inácio de Loyola - fundador da Companhia de Jesus - ao longo do período compreendido entre 1521 e 1539, respectivamente, ano em que sofreu um grave ferimento na perna ficando convalescente $\mathrm{e}$ ano que antecedeu o reconhecimento oficial da Companhia de Jesus pela Igreja Católica. Os Exercícios Espirituais são resultado de cerca de duas décadas de peregrinações, 
meditações e estudos de seu autor; e foram estruturados a partir de sua experiência apostólica e de reflexão. Inácio se convenceu de que os procedimentos e métodos que desenvolvera, a fim de potencializar sua capacidade de interiorização, possuíam valor universal e poderiam ser transmitidos a outros para servir como ferramenta evangelizadora.

Nos Exercícios Espirituais Inácio de Loyola compilou uma série de procedimentos e artifícios mentais que utilizava para catalisar a reflexão e o auto-exame, bem como uma série de prescrições que diziam respeito a um regime concreto de horários, distribuições espaciais e atitudes corporais com o intuito de que pudessem servir como um guia para regular afeições desordenadas e superar fraquezas. Neste sentido, os que desejassem controlar suas paixões terrenas e aproximar-se de Deus, deveriam colocar-se em exercício a fim de alcançar seus objetivos. Em uma palavra, exercício é o elemento chave do projeto de Inácio de Loyola. Quando se pensa em exercícios, logo se entende que há um treino. Em razão disso os Exercícios Espirituais não se tratam apenas de uma oração, mas sim, de um trabalho planificado, com orientação e com acompanhamento. É importante frisar que todo aquele que se submete aos Exercícios o faz mediante o acompanhamento de um orientador, que tem por objetivo auxiliar o indivíduo em seu discernimento e zelar pelo bom andamento das atividades.

Os Exercícios Espirituais contemplam a um só tempo a mente e o corpo; e podem ser definidos como um manual prático que estabelece um conjunto de normas e procedimentos que dentro de um ambiente de oração visam favorecer no exercitante o exame de consciência. Buscando-se traçar o itinerário pelo qual o indivíduo deve passar na realização dos Exercícios Espirituais completos, nota-se uma lógica muito peculiar de conversão que pode ser observada durante as suas 4 Semanas. Cada Semana possui objetivos específicos que devem ser alcançados pelo exercitante a partir da reclusão, da meditação, do exame de consciência, da oração e da contemplação. Nota-se que os Exercícios pautam-se na ideia pedagógica de uma progressão metódica, com as Semanas articuladas entre si de maneira a comporem um conjunto orgânico capaz de conduzir o exercitante de maneira dinâmica e estruturada.

A primeira Semana é caracterizada como a via Purgativa. Nela o exercitante deve refletir acerca de seus pecados, utilizando preponderantemente o exame de consciência e a meditação que, ao menos em tese, devem ser capazes de conduzi-lo à contrição. Nesta parte dos Exercícios é buscado um afastamento do estilo de vida anterior, assim, o reconhecimento dos pecados e o imperativo do arrependimento são os passos iniciais para a adesão a uma nova vida guiada pelos valores cristãos. Em seu auto-exame, o exercitante deve registrar minuciosamente suas faltas para com Deus, bem como seus progressos na fé, construindo uma espécie de arquivo que servirá como referência para futuras aferições acerca de seu desenvolvimento espiritual. Essa característica distintiva do exame de consciência proposto por Inácio de Loyola trouxe um novo elemento para a mística católica, qual seja, o do registro metódico de informações acerca do indivíduo. Esse procedimento é marcadamente característico da racionalidade Moderna e traria contribuições para a constituição do conceito de autonomia individual. A primeira Semana é o momento em que o indivíduo é afastado de seu estilo de vida anterior e é apresentado a uma nova possibilidade - a ser construída a partir da identificação com a figura de Jesus Cristo (PALAORO, 1992; ARNAUT DE TOLEDO, 1996; O’NEIL; DOMÍNGUEZ, 2001).

A segunda Semana é entendida como a via Iluminativa. Nesta Semana, as atividades são organizadas metodicamente a fim de favorecer a identificação do exercitante com a figura de Cristo. Após a meditação acerca do tipo de vida a que a prática do pecado conduz, as contemplações da vida de Cristo levam o indivíduo ao confronto com a 
possibilidade de escolha de um novo modelo para sua vida. (GUILLERMOU, 1973; O’NEIL; DOMÍNGUEZ, 2001). Neste ponto, o trabalho é no sentido de eliminar a vontade subjetiva para, após o "encontro com Cristo", reencontrá-la muito mais fortalecida (ARNAUT DE TOLEDO, 1996). Finalmente, a partir da introdução de questões relacionadas ao papel do homem na difusão da obra de Deus, chega-se ao ponto alto da Segunda Semana: a Eleição. Nesse momento o exercitante é convocado a responder acerca do chamado de Deus, devendo aderir ou não à Sua obra. Conforme Mateo (1998, p. 507, tradução nossa), para Inácio de Loyola: "O homem livre, modelador e escultor de si mesmo, tem que encontrar um critério de eleição [...]". A Eleição serve como um divisor de águas nos Exercícios, visto que até esse momento o exercitante foi preparado para realizar essa escolha fazendo uso do maior discernimento possível. A partir desse ponto, a ênfase dos Exercícios se dará na preparação do indivíduo para que assuma sua missão apostólica. No sentido de orientar a Eleição, Inácio de Loyola (2000, p. 71) afirma que: "Em toda boa eleição, o olhar de nossa intenção deve ser simples, quanto depender de nós. Somente devo olhar aquilo para o qual sou criado: o louvor de Deus nosso Senhor e minha salvação". Reafirma assim a concepção religiosa de homem que orienta os Exercícios.

A terceira Semana inaugura a via Unitiva dos Exercícios Espirituais, tendo como finalidade principal a confirmação da escolha feita ao final da Semana anterior. Para tal, as atividades buscam promover no exercitante uma experiência pessoal com Deus, centrando seus pontos de oração na Paixão de Cristo e levando o indivíduo a um momento de profunda introspecção. De certa forma, promove-se na terceira Semana inicialmente um estado de mortificação - em razão da contemplação do sofrimento de Jesus - para que, em seguida, esse estado de espírito sirva como mais um elemento para inclinar o exercitante à adesão à fé católica ou seu fortalecimento (O’NEIL; DOMÍNGUEZ, 2001). Há um item muito peculiar ao final dessa Semana, a saber, as Regras para ordenar-se no comer, em que Inácio de Loyola apresenta um diretório com indicações no sentido do cultivo da temperança. A partir desse ponto, há uma marcante guinada nos Exercícios, com as penitências sendo progressivamente substituídas pela ideia de temperança nos atos cotidianos (INÁCIO DE LOYOLA, 2000).

Finalmente, na Quarta Semana, ainda por meio da via Unitiva, há um coroamento de todo o processo dos Exercícios. A partir da exaltação do Mistério Pascal, o indivíduo é levado a celebrar a vitória da ressurreição de Cristo e, nesse clima de júbilo, é instruído a respeito de como levar uma vida de apostolado em consonância com a fé católica. Para tanto, a Quarta Semana lança mão da amenidade nas atividades e determinações, buscando com isso contribuir para o favorecimento do bem estar mental, físico e espiritual do exercitante. Essa nova estratégia tem como intenção proporcionar ao indivíduo intensa consolação, favorecendo uma experiência jubilosa ao fim dos Exercícios ${ }^{7}$. Imbuído desse bem estar, espera-se que o indivíduo efetive sua transformação espiritual, tornando-se capaz de lançar mão em sua vida cotidiana de todos os elementos aprendidos ao longo dos Exercícios (O’NEIL; DOMÍNGUEZ, 2001).

Este processo por etapas, característico dos Exercícios, pressupõe que o indivíduo passe por fases de aprendizagem e adquira conhecimento por meio de uma pedagogia do esforço. Associado a isso, o processo é dinamizado por uma espécie de diálogo pedagógico com o orientador que, além de realizar as preleções iniciais e as avaliações para determinar o ritmo e o andamento das atividades, também deve servir para o indivíduo como um auxiliar na jornada de aprendizagem acerca de si mesmo e das coisas espirituais. Trata-se de uma pedagogia dinâmica, progressiva e dialógica, em que o papel ativo do indivíduo é um pressuposto. 


\section{O modelo pedagógico da Companhia de Jesus: a Ratio Studiorum}

A proposta inicial de Inácio de Loyola com a criação da Companhia de Jesus, a saber, a de ser uma Ordem missionária que levaria a palavra de Deus com engajamento efetivo na luta contra os infiéis, requeria homens bem formados e capazes de unir o ardor do trabalho apostólico à formação sólida nas humanidades, filosofia e teologia. Para que tais homens pudessem desenvolver essas habilidades, fez-se necessário a criação de casas de formação para os neófitos. Embora as primeiras empreitadas educativas da Companhia de Jesus dissessem respeito às casas de formação de novos membros da Ordem, logo os colégios passaram a ser frequentados por "externos" que se interessavam pelo conhecimento transmitido nas instituições (O’NEILL; DOMÍNGUEZ, 2001). Ao passo disso, A Maior glória de Deus, um dos elementos fundantes da espiritualidade inaciana, foi, desde o início, ao menos no plano conceitual, o princípio orientador da obra pedagógica jesuítica. Isto demonstra a indissociabilidade entre as esferas apostólica e educativa da Companhia, bem como a íntima relação entre a mística e o projeto pedagógico da Ordem. O modo como os estudantes deveriam se dividir entre atividades religiosas e de estudo e a íntima relação entre essas duas esferas, fica evidenciada em uma carta de Inácio de Loyola ao Pe. Antônio Brandão, datada do ano de 1551. Nela Inácio, bem ao seu estilo, estabelece um protocolo detalhado da mencionada divisão:

a finalidade do estudo de um escolástico no Colégio, [...] é a ciência, para poder servir à maior glória de Deus N. S. e ajuda do próximo. Isto exige o homem todo, que não se daria totalmente ao estudo se empregasse longo tempo na oração. Portanto, aos escolásticos não-sacerdotes, quando não intervém nenhuma tentação que inquiete ou uma grande devoção, basta uma hora, além da missa. No decurso dela, pode meditar, enquanto o sacerdote recita as orações em silêncio. Na hora sobredita pode comumente rezar as horas de Nossa Senhora ou alguma outra oração, ou exercitar-se na meditação, segundo a direção do Reitor. Ao Sacerdote Escolástico bastam a missa, a recitação obrigatória do Ofício Divino e os exames de consciência; poderá tomar mais meia hora, se tiver muita devoção. (INÁCIO DE LOYOLA,1990, p. 84).

De acordo com O’Malley (2004), a Companhia cerca de uma década após a sua fundação já reconhecia plenamente a educação como uma estratégia privilegiada no sentido de propagar a obra de Deus. Educação e apostolado se constituíram assim, desde o princípio da Ordem, como as duas instâncias fundamentais da missão pastoral jesuítica e também o próprio carisma da Ordem. Assim, não é possível pensá-las separadamente. Inácio de Loyola ao vislumbrar o potencial que um amplo projeto educativo poderia ter naquele momento, esforçou-se pessoalmente no sentido de reunir os maiores talentos da Companhia de Jesus em torno deste ministério. Neste sentido, o colégio de Messina fundado em 1548 na Sicília, é o grande marco do início da empreitada educacional dos jesuítas, uma vez que foi aberto para externos. Embora precedido cronologicamente pelos colégios de Goa (1542) e Gândia (1546), que se destinavam à formação do quadro da Companhia, distinguiu-se pela sua excelência e pelos objetivos mais ambiciosos; e se tornou referência para o desdobramento do projeto dos jesuítas no ministério da educação. Por ocasião da morte de Inácio de Loyola (1556), a Companhia já operava algo em torno de 35 colégios, o que demonstra a rápida expansão que as instituições de ensino comandadas pelos jesuítas experimentaram (OLIN, 1994). Acerca deste impacto e da 
importância que os colégios jesuíticos tiveram na história da Igreja Católica, O’Malley afirma que:

Os jesuítas abriram uma nova era para a educação formal no catolicismo romano. A Companhia foi a primeira ordem religiosa a empreender sistematicamente, como um ministério primário e autônomo, a operação de colégios totalmente desenvolvidos para quaisquer estudantes, leigos ou clérigos, que escolhessem vir a eles. Isso marcou uma ruptura decisiva com os primeiros padrões de relação entre a igreja e as instituições educacionais (O'MALLEY, 2004, p. 372).

É marcante, portanto, o papel histórico desempenhado pelos jesuítas no campo da educação, bem como o amplo alcance que o modelo jesuítico de ensino obteve em vários lugares do mundo - em virtude das incursões missionárias. Influenciaram diferentes culturas, religiões e mesmo outras Ordens que passaram a conceber de modo diferenciado o papel do ensino. Mesmo a educação Protestante fez referência ao estilo pedagógico jesuítico. Também o fato dos colégios jesuíticos serem gratuitos e abertos - conseguindo manter-se a partir de doações de pessoas importantes e de acordos com governantes - foi relevante para a amplitude de sua influência.

A Companhia de Jesus, em pouco tempo se fez notar pela qualidade de seus colégios e professores e experimentou um grande crescimento da obra educativa. Desta forma, fazia-se mais do que nunca urgente a redação de normas gerais que regulamentassem de maneira detalhada o modo como se organizaria a instituição, o estudo e as atividades atinentes. Neste sentido, surgiu a preocupação de se criar um estilo pedagógico alinhado aos preceitos orientadores da Ordem, de tal forma que se fortalecesse a harmonia entre o aspecto eminentemente religioso e o pedagógico. Conforme Schmitz (1994, p. 56): “O fim das instituições de ensino dos jesuítas está, pois, bem claro: é a glória de Deus e a ajuda aos próximos. Isto naturalmente se alcançará através da atividade docente e de outras que possam ser exercidas".

A IV parte das Constituições da Companhia de Jesus - Como instruir nas letras e em outros meios de ajudar o próximo os que permanecem na Companhia - em vigor desde 1552, deu as diretivas iniciais para a prática pedagógica nas instituições comandadas pelos jesuítas (CONSTITUIÇÕES..., 2004). Pode-se falar na existência de uma preocupação explícita com a educação desde muito pouco tempo após a fundação da Ordem, havendo uma regulamentação do modo de organização dos estudos, do currículo, da disciplina e de uma metodologia de ensino própria desde então. Já existiam nas Constituições, inclusive, referências à necessidade da elaboração de um tratado que regulamentasse de maneira pormenorizada as questões referentes à prática pedagógica nos colégios da Companhia.

As horas das aulas, com a ordem e o método próprio, os exercícios de composição literária (que devem ser corrigidos pelos professores) ou de discussão em todas as matérias, a declamação pública em prosa e verso, tudo isso se indicará em pormenor em tratado à parte, aprovado pelo Geral, ao qual a presente Constituição remete ao leitor. Dizemos somente que esse tratado deve adaptar-se aos lugares, aos tempos e às pessoas, embora seja para desejar, quanto possível, que se chegue a uma ordem comum (CONSTITUIÇÕES..., 2004, p. 141-142).

Paiva e Puentes (2000) afirmam que a Companhia viu na dedicação ao campo da educação uma maneira de se adequar às exigências de seu tempo, lutando pela reforma da sociedade. Tanto em suas atividades espirituais como temporais, os jesuítas buscavam a 
perfeição; embasando suas ações e proposições no princípio de que os homens deveriam buscar em tudo melhor servir a Deus. Isto fica claro no Proêmio da IV parte das Constituições:

O fim que a Companhia tem diretamente em vista é ajudar as almas próprias e as do próximo a atingir o fim último para o qual foram criadas. Este fim exige uma vida exemplar, doutrina necessária, e maneira de apresentar. Portanto, uma vez que se reconhecer nos candidatos o requerido fundamento de abnegação de si mesmos e o seu necessário progresso na virtude, devem-se procurar os graus de instrução e o modo de utilizá-la para ajudar a melhor conhecer e servir a Deus nosso Criador e Senhor (CONSTITUIÇÕES..., 2004, p. 115).

Há muita semelhança deste trecho com o Princípio e Fundamento dos Exercícios Espirituais: "O ser humano é criado para louvar, reverenciar e servir a Deus nosso Senhor e, assim, salvar-se. [...] desejando e escolhendo somente aquilo que mais nos conduz ao fim para o qual somos criados" (INÁCIO DE LOYOLA, 2000, p.23). Pode-se identificar a existência de uma linha orientadora comum, tanto para a prática espiritual como para a prática educativa da Companhia de Jesus, estabelecendo-se uma íntima relação entre essas duas instâncias desde a elaboração dos primeiros documentos da Ordem.

Embora a IV parte das Constituições tratasse do campo educacional, suas diretivas gerais não prescindiam de uma pormenorização que uniformizasse a pedagogia jesuítica. Assim, a fim de suprir a necessidade de uma regulamentação para os colégios, foi elaborada a Ratio atque Studiorum Societatis Iesu (1599) - código de ensino que orientou a organização e as atividades dos colégios jesuíticos espalhados por todo o mundo. Schmitz (1994, p. 98) esclarece que o objetivo deste documento "[...] era oferecer a todas as escolas e colégios, bem como universidades da Companhia, normas seguras e uniformes de procedimento e uma metodologia adequada aos seus objetivos e à sua ação e obras educativas". Acerca da necessidade de uma ordenação de estudos detalhada. Franca se posiciona da seguinte forma:

Só uma codificação de leis e processos educativos poderia evitar o grave inconveniente das mudanças freqüentes que a grande variedade de opiniões e preferências individuais acarretaria, com a sucessão de professores e prefeitos de estudos. Só um texto autorizado e imperativo, elaborado por uma experiência amadurecida, cortaria pelas tentativas infrutíferas dos que ensaiavam as primeiras armas nas lides do magistério (FRANCA, 1952, p. 17).

O fato é que no ano de 1750 a Companhia de Jesus chegou a dirigir 578 colégios e 150 seminários, ou seja, um total de 728 casas de ensino (FRANCA, 1952). Frente a isto, não se pode negar a influência exercida pelos jesuítas na educação Moderna, com a Ratio Sudiorum, a partir da irradiação espontânea de seus preceitos e determinações, tendo influenciado a formação e o desenvolvimento dos sistemas educativos da época.

De acordo com Klein (1997), a elaboração da Ratio Studiorum pode ser dividida em dois blocos. O primeiro consistiu de uma fase de levantamento, verificação e adaptação do material pedagógico produzido na Ordem e se deu entre os anos de 1548 e 1583 . No segundo, entre 1584 e 1599, foram elaboradas duas versões provisórias da Ratio - 1586 (não publicada) e 1591- e, finalmente, a versão definitiva que veio a público no ano de 
1599. A Ratio Studiorum dispõe na longa estrutura de regras apresentadas a seguir, o projeto de Organização e plano de estudos da Companhia de Jesus:

- Regras do Provincial

- Regras do Reitor

- Regras comuns a todos os professores das faculdades superiores

- Regras do professor de Sagrada Escritura

- Regras do professor de língua hebraica

- Regras do professor de teologia

- Regras do professor de casos de consciência

- Regras do professores de filosofia

○ Regras do professor de filosofia

- Regras do professor de filosofia moral

- Regras do professor de matemática

- Regras do prefeito de estudos inferiores

- Normas da prova escrita

- Normas para a distribuição de prêmios

- Regras comuns aos professores das classes inferiores

- Regras do professor de retórica

- Regras do professor de humanidades

- Regras do professor da classe superior de gramática

- Regras do professor da classe média de gramática

- Regras do professor da classe inferior de gramática

- Regras dos escolásticos da nossa Companhia

- Diretivas para os que repetem privadamente a teologia em dois anos

- Regras do ajudante do professor ou bedel

- Regras dos alunos externos da Companhia

- Regras da academia

- Regras do prefeito da academia

- Regras da academia dos teólogos e filósofos

- Regras do prefeito da academia dos teólogos e filósofos

- Regras da academia dos retóricos e humanistas

- Regras da academia dos gramáticos

Conforme se pode perceber, as regras da Ratio Studiorum são numerosas e, para além disso, possuem conteúdos que se assemelham - nos vários ofícios de que tratam. Em virtude disso, optou-se neste artigo pela não utilização do método de abordar separadamente cada um dos tópicos da Ratio com a descrição de item por item, mas sim, por abordar os conceitos que perpassam o documento.

Pode-se notar na Ratio Studiorum uma disposição pormenorizada de regras, normas e diretivas que visam regulamentar todas as instâncias e atividades nas instituições educativas a cargo da Companhia de Jesus. Tratava-se de delimitar os procedimentos e competências a serem trabalhados. Entretanto, o espírito da educação jesuítica não pode ser entendido sem que concomitantemente se contemple os Exercícios Espirituais, visto que a Ratio pressupõe os valores expressos nesse documento.

Em sua regulamentação, os jesuítas não se pretenderam revolucionários no campo educativo, e sim, ajustaram-se às demandas de sua época produzindo um documento que satisfizesse ao máximo as exigências do Mundo Moderno que surgia. Portanto, a existência de regras que delimitavam a ação de modo afirmativo e de uma série de prescrições 
práticas e minuciosas, por si só, já davam indício da futura influência que a Ratio Studiorum teria na pedagogia da Modernidade. Acerca do detalhamento e da minúcia das determinações da Ratio Studiorum, Manacorda (2002, p. 202) menciona a rígida regulamentação de "[...] todo sistema escolástico jesuítico: a organização em classes, os horários, os programas e a disciplina [...]", ou seja, há uma referência a uma regulamentação do espaço, do tempo e do conteúdo, a fim de se obter o resultado desejado via um controle dissolvido nas ordenações do dia a dia. Leonel Franca expressa de maneira sintética o sentimento que um leitor menos avisado pode experimentar frente ao primeiro contato com a Ratio:

Para quem, pela primeira vez, se põe em contacto com o Ratio, a impressão espontânea é quase uma decepção. Em vez de um tratado bem sistematizado de pedagogia, que talvez esperava, depara com uma coleção de regras positivas e uma série de prescrições práticas minuciosas. De fato, o Ratio não é um tratado de pedagogia, não expõe sistemas nem discute princípios (FRANCA, 1952, p. 43).

É importante frisar que a Ratio Studiorum, foi influenciada pelo Modus Parisiensis, que era considerado por Inácio de Loyola o melhor método de ensino que havia experimentado em sua vida de estudante. Franca (1952, p. 8) escreve que: "Em matéria de repetições disputas, composições, interrogações e declamações o método adotado e seguido foi deliberadamente o de Paris [...]". Inclusive, o colégio de Messina fundado em 1548 pelo Pe. Jerônimo Nadal, já tinha sua regulamentação interna inspirada no modelo parisiense de estudo.

A Ratio Studiorum foi elaborada numa espécie de centralismo democrático onde, por meio de correspondências, as propostas eram enviadas aos colégios que, na sequência, devolviam com sugestões e correções (ARNAUT DE TOLEDO; RUCKSTADTER, 2003). Os encarregados diretos da redação da Ratio ficavam incumbidos de re-elaborar o texto e de remetê-lo novamente aos colégios a fim de que o processo se repetisse até o momento em que se chegasse a termo. Este foi um processo exaustivo que resultou em um dos documentos mais importantes da pedagogia Moderna. Entretanto, o que não se pode perder de vista é que:

Esse código material que é a Ratio Studiorum não era mais que a resposta metodológica a uma série de princípios ou finalidades prévias que constituíam o ideal educativo dos primeiros jesuítas. Sem ter presente esse objetivo final, não se pode entender os <<para quês >> nem os <<porquês〉> das Regras da Ratio Studiorum. Prescindindo deles, carecem de sentido os <<como $>>$ ou as práticas prescritas por essas Regras. Seria estudar um corpo - uma letra morta - sem o espírito que lhe deu vida (BERTRÁN-QUERA, 1986, p. 17, tradução nossa).

Desta forma, fortalece-se a ideia de que a Ratio Studiorum não pode ser entendida se dissociada do modo como se organizavam os preceitos da base espiritual jesuítica. Os Exercícios Espirituais podem ser considerados em si mesmos como uma espécie de pedagogia, uma vez que métodos de oração e de reflexão são ensinados a fim de propiciar ao exercitante condições de realizar suas escolhas - algo bem ao estilo da espiritualidade inaciana. Com efeito, é uma pedagogia a partir da qual deveria surgir um crescimento espiritual e também intelectual e que implicasse na mudança do estilo de vida, contemplando, em última instância, o câmbio para uma vida devota e a serviço de Deus. 


\section{Da mística à pastoral educacional: os Exercícios Espirituais e os elementos conceituais da composição da Ratio Studiorum}

O primeiro ponto em que se pode verificar a convergência entre os Exercícios Espirituais e a Ratio Studiorum é o foco no indivíduo e no exercício pessoal. Embora todas as etapas estejam planejadas, a responsabilidade é pessoal, cabendo ao indivíduo a partir de sua iniciativa e trabalho atingir os objetivos estabelecidos. Esta característica é um dos princípios orientadores do pensamento jesuítico e está presente tanto no âmbito espiritual como no educacional. Pode-se confirmar essa ideia, inclusive, pela correspondência de Inácio de Loyola. No ano de 1555 em uma carta a Bartolomeu Romano - estudante jesuíta morador do colégio de Ferrara -, Inácio respondia às reclamações do neófito, que anteriormente escrevera culpando os demais pelo seu desânimo para com o estudo e para com as práticas espirituais. A carta de Inácio pode comprovar que o foco no indivíduo e em seu trabalho pessoal foi desde o princípio um dos preceitos da orientação dos estudos e da prática religiosa da Companhia de Jesus. Assim, o fundador da Companhia escreveu:

\footnotetext{
Está muito enganado se pensa que a causa de não conseguir aquietar-se nem dar fruto no caminho do Senhor está no lugar ou nos Superiores ou nos irmãos. Isso vem de dentro de você e não de fora, isto é, da sua pouca humildade, pouca obediência, pouca oração e, enfim, pouca mortificação e pouco fervor para avançar no caminho da perfeição. Pode mudar de lugar, de Superiores e de irmãos; mas se não muda o seu homem interior, nunca agirá bem e em qualquer lugar será o mesmo, até que chegue a ser humilde, obediente, devoto, mortificado no seu amor-próprio. De modo que procure esta mudança e não outra. Digo que procure mudar o homem interior e dominá-lo como a servo de Deus, e não pense em nenhuma mudança externa, porque ou você será bom aí, em Ferrara, ou não será bom em nenhum Colégio (INÁCIO DE LOYOLA, 1990, p. 135-136).
}

Nota-se que há um foco nas qualidades interiores do indivíduo, cabendo à sua iniciativa e ao seu esforço a mudança de suas disposições. Assim, é pelo árduo trabalho regular e pela realização de exercícios constantes e variados que a pedagogia jesuítica seja na prática espiritual seja no ensino dos colégios - estimula o indivíduo. Uma espécie de estado de alerta permanente é induzido, o que implica em uma aprendizagem que se efetiva pela via de um amplo envolvimento do sujeito, não havendo espaço para a passividade.

Outro ponto fundamental do pensamento jesuítico, e que é pertinente aos dois documentos estudados, é o estabelecimento de metas. Seja pela proposição de objetivos específicos a serem alcançados em cada uma das Semanas dos Exercícios Espirituais, ou pela organização de um currículo com conteúdos bem delimitados e organizados de modo progressivo como na Ratio Studiorum. Na lógica interna dos Exercícios, aquele que deseja cumprir as quatro Semanas verdadeiramente, deve ter logrado êxito em todos os pontos propostos, e, a partir de suas potências cognitivas e da aplicação dos sentidos, ter alcançado o discernimento e realizado sua Eleição de modo consistente e embasado com adesão à obra de Deus. Este processo se dá a partir da inserção do indivíduo em um campo de forças em que sua liberdade pessoal é continuamente modulada pelas determinações exteriores - que neste caso são o conteúdo, a dinâmica e a estrutura dos Exercícios - tal qual uma estratégia ampla de ensino, que conduz o sujeito a um ponto desejado. Evidentemente, esta técnica exige um tempo para se estabelecer. Assim: 
[...] aquele que faz os Exercícios vive em meio a uma difícil, mas necessária conciliação entre o "fincar raízes" e o avançar; trata-se de viver a experiência do peregrino: prosseguir sempre, para, avaliar, novamente aventurar-se. As meditações e contemplações se concatenam numa ordenada progressão; mas ao mesmo tempo fazse necessário retornar constantemente àquilo que já foi vivido, experimentado. É o convite a parar para uma maturação. Somente depois a pessoa estará pronta para abrir-se ao novo. Esta circularidade, que confere à experiência inaciana uma unidade própria, implica um ritmo de re-velação e re-petição, estruturado em etapas que exigem um tempo interior para a assimilação e maturação da mensagem ou mistério a considerar (PALAORO, 1992, p. 66).

O currículo concebido pela Ratio Studiorum também contempla a progressão gradual do indivíduo, que, acompanhado e avaliado de perto pelos professores, paulatinamente passaria a graus mais adiantados. Conforme Franca (1952, p. 48), os estágios a serem alcançados "[...] representam menos uma unidade tempo (1 ano) do que uma determinada soma de conhecimentos adquiridos. Só podia ser promovido à classe superior o aluno que os houvesse assimilado integralmente". Essa afirmação encontra-se perfeitamente alinhada com o preceito contido nos Exercícios de que o indivíduo só poderia passar à Semana seguinte se tivesse alcançado a contento os objetivos propostos para a Semana anterior.

Neste sentido, outros dois pontos fundamentais compõem o campo conceitual que orienta os Exercícios e a Ratio, a saber, a documentação das atividades - espirituais ou de estudos - e a avaliação constante - por parte do orientador ou do professor. Nos Exercícios Espirituais Inácio de Loyola propõe o registro por escrito dos pecados e defeitos particulares que o exercitante percebe em si mesmo. Inclusive, há no manual uma espécie de tabela composta de sete linhas que serviria para que o indivíduo pudesse anotar e depois comparar seu "desempenho". São dadas as seguintes orientações para o entendimento e uso da tabela, bem como para o registro e análise dos resultados:

A primeira linha significa o primeiro exame; a segunda, o segundo. Por isso, à noite, observar se houve melhora da primeira para a segunda linha, isto é, do primeiro para o segundo exame. Comparar o segundo dia com o primeiro, isto é, os dois exames do dia presente com os do dia anterior. Observar se houve melhora de um dia para o outro. Comparar uma Semana com a outra. Observar se na Semana presente houve melhora em relação à anterior (INÁCIO DE LOYOLA, 2000, p. 26-27).

A Ratio Studiorum segue este modelo baseado no registro para a posterior comparação de resultados, determinando que "[...] todos os dias, apresentem-se, com excepção do sábado, trabalhos escritos [...]” (RATIO STUDIORUM, 1952, p. 184). Além da documentação diária do estudo, a Ratio determina pormenorizadamente os procedimentos de exame demonstrando a especial atenção que dá a esse procedimento. Conforme Najmanovich (2001), uma das modificações que se pode notar na passagem da Idade Média para a Modernidade é a construção, difusão e imposição de instrumentos de medida intimamente vinculados ao procedimento de comparação. Havia um padrão geral ao qual se havia chegado até aquele momento, e a partir desta referência devia ser verificado se o caso particular se adequava à norma ou se era desviante. O indivíduo 
passava a ser algo mensurável dentro de um eixo de coordenadas. A partir disso, tomandose como base os resultados mensurados, caberia a premiação ou correção do indivíduo.

$\mathrm{Na}$ execução desta prática o papel do professor e do orientador era muito importante. Seria função do orientador definir a atividade, auxiliar e estimular o exercitante no sentido de sua correção. Charmot (1952, p. 101, tradução nossa) afirma que no âmbito educativo da Companhia de Jesus "[...] o professor trabalhará em segundo plano, para ajudar o personagem do primeiro plano [...] a progredir em sua evolução própria. Pondo-se totalmente a serviço do aluno". Orientador e professor possuem funções análogas, uma vez que devem se comportar de modo a estimular e auxiliar o desenvolvimento pessoal do exercitante ou do aluno. Para tal, principalmente o professor, poderia utilizar duas estratégias inovadoras da pedagogia jesuítica: a emulação e a premiação. A emulação se daria principalmente através do desafio entre os alunos, ou entre grupos de alunos. $\mathrm{O}$ seguinte trecho da Ratio Studiorum é bastante ilustrativo:

O desafio que poderá organizar-se ou por perguntas do professor e correção dos êmulos, ou por perguntas dos êmulos entre si deve ser tido em grande conta e posto em prática sempre que o permitir o tempo a fim de alimentar uma digna emulação, que é de grande estímulo para os estudos. Poderá bater-se um contra um, ou grupo contra grupo, sobretudo dos oficiais, ou um poderá provocar a vários; em geral um particular provocará outro particular, um oficial outro oficial; um particular poderá às vezes desafiar um oficial e se o vencer conquistará a sua graduação, ou outro prêmio ou símbolo de vitória, conforme o exigir a dignidade da classe e o costume da região (RATIO STUDIORUM, 1952, p. 187).

Muito interessante notar a premiação aos vencedores destas disputas. Ainda em outro ponto a Ratio recomenda ao professor que estimule "[...] em suas aulas os alunos com pequenos prêmios particulares, ou outros símbolos de vitória dados pelo Reitor do Colégio e que sejam merecidos por quem venceu o adversário, repetiu ou aprendeu de cor um livro inteiro, ou realizou algum outro esforço notável" (RATIO STUDIORUM, 1952, p. 174). Pode-se perceber, portanto, que se trata de uma estratégia onde são estimulados os comportamentos desejados, buscando sempre manter os estudantes alerta e em atividade.

Também a rígida distribuição do tempo e as regulamentações espaciais presentes nos dois documentos são elementos de controle dos indivíduos. Franca (1952) afirma que o tempo é minuciosamente distribuído na Ratio Studiorum, com as diversas atividades e exercícios escolares sendo organizados de modo variado durante o dia a fim de se alcançar um melhor aproveitamento. Por exemplo: a Ratio Studiorum determina 5 horas de aulas diárias, divididas entre manhã e tarde, além de atividades suplementares de leituras; já os Exercícios Espirituais determinam que:

$\mathrm{O}$ primeiro exercício será feito à meia-noite. $\mathrm{O}$ segundo pela manhã, ao levantar-se. $\mathrm{O}$ terceiro, antes ou depois da Missa, contanto que seja antes de alimentar-se. O quarto, ao tempo das vésperas. O quinto, uma hora antes do jantar (INÁCIO DE LOYOLA, 2000, p. 41).

O tempo do indivíduo é preenchido a fim de que se desvie o menos possível do objetivo que se busca alcançar. Tanto nos Exercícios como na Ratio o controle é exercido menos pela repressão que pela positividade das determinações dissolvidas no cotidiano.

Já com relação ao controle do espaço, nos Exercícios Espirituais podem ser inclusive encontradas determinações acerca das condições de claridade e ventilação no 
ambiente em que a prática será feita. O trecho a seguir dá uma boa ideia da minúcia dos Exercícios em algumas de suas prescrições: "Entrar em contemplação, ora de joelhos, ora prostrado por terra, ora deitado com o rosto voltado para cima. Também sentado ou de pé. Indo sempre em busca do que quero" (INÁCIO DE LOYOLA, 2000, p.44). Ou seja, determina-se a atividade a ser realizada, o modo como o corpo deve estar posicionado, bem como a sequência das alterações de posição.

Atuando nessas diversas instâncias, os Exercícios modulam a experiência, sendo capazes de deixar o indivíduo mais propenso a experimentar este ou aquele sentimento. Já na organização dos estudos, a regulamentação dos procedimentos durante a realização de prova é bastante ilustrativa para a compreensão de como se dava o controle do espaço: "indicado o assunto da prova, antes de a terminar e entregar, ninguém saia da aula nem fale com outrem, dentro ou fora do ginásio; se for necessário sair, com licença, deixe-se tudo o que se houver escrito em mãos de quem estiver encarregado da aula" (RATIO STUDIORUM, 1952, p. 179). Nota-se que os deslocamentos dentro do colégio eram regulamentados no sentido de evitar qualquer desordem que pudesse atrapalhar o bom andamento das atividades de estudo, cabendo ao professor atentar para que as determinações fossem cumpridas contribuindo assim para a manutenção da ordem. Pode-se afirmar a existência de uma estratégia de controle espacial muito parecida nos Exercícios Espirituais e na Ratio Studiorum, tendo como principal característica a regulamentação pormenorizada de procedimentos a serem adotados pelos indivíduos em diferentes situações.

A existência de uma estrutura de estudos definida na Ratio Studiorum não implica que o sistema de ensino dos jesuítas fosse estanque, uma vez que eram contemplados ajustes conforme as necessidades que surgissem na cultura local. Assim chega-se a outro ponto comum entre Exercícios e Ratio, a saber, o da adaptação de procedimentos e conteúdos. Isto está claramente previsto na seguinte passagem do texto da Ratio Studiorum:

[...] na diversidade de lugares, tempos e pessoas pode ser necessária alguma diversidade na ordem e no tempo consagrado aos estudos, nas repetições, disputas e outros exercícios e ainda nas férias, se julgar conveniente, na sua Província, alguma modificação para maior progresso das letras, informe o Geral para que se tomem as determinações acomodadas a todas as necessidades, de modo, porém, que se aproximem o mais possível da organização geral dos nossos estudos (RATIO STUDIORUM, 1952, p. 132).

Essa orientação no sentido de adaptar os procedimentos e o conteúdo de acordo com as capacidades individuais e o contexto em que a atividade estivesse inserida, é encontrada na seguinte passagem dos Exercícios Espirituais: "Os exercícios espirituais devem ser adaptados à disposição das pessoas que desejam fazê-los. Isto é, conforme a sua idade, instrução ou talento" (INÁCIO DE LOYOLA, 2000, p. 18). Além disto, Inácio de Loyola também recomendava aos indivíduos que não dispunham de tempo para se dedicar integralmente aos Exercícios - em razão de se ocuparem de negócios importantes -, que dedicassem uma hora e meia por dia a tal prática. Esse princípio de adaptação desmente as proposições que imputam aos jesuítas normas inflexíveis, tanto no que diz respeito à sua espiritualidade como ao seu ministério educativo. Adaptar-se às características individuais, às demandas do mundo temporal, bem como às peculiaridades das diferentes culturas, mostra que os jesuítas tinham práticas eminentemente Modernas. Uma possível perda de 
coesão oriunda da permissão da realização de adaptações, não se concretizou principalmente em virtude da rígida hierarquia da Companhia de Jesus e do grande senso de obediência de seu corpo de religiosos. Assim sendo, a unidade interna da Ordem, bem como a sua relação com a totalidade da Igreja não foi abalada.

A disciplina foi um dos conceitos fundamentais na orientação das práticas dos jesuítas. No ano de 1552 em carta ao Pe. Diogo Mirão - nomeado Provincial da Companhia em Portugal em 1551 -, Inácio de Loyola dá um claro exemplo de como a obediência e a total diligência aos assuntos de Deus eram pedras angulares para a Ordem:

Vemos por experiência que talentos medíocres e menos que medíocres muitas vezes são instrumentos que produzem frutos muito notáveis e sobrenaturais, porque são obedientes e, por meio desta virtude, se deixam mover e possuir pela poderosa mão do autor de todo o bem. E, ao contrário, se vêem grandes talentos trabalharem por si mesmos, isto é, pelo seu amor-próprio, o pelo menos não se deixam mover bem por Deus N. S. por meio da obediência a seus superiores, e por isso não produzem efeitos proporcionais à sua mão onipotente de Deus N. S., que não os aceita como instrumentos [...]. (INÁCIO DE LOYOLA, 1990, p. 101102).

A disciplina era também concebida como uma qualidade mais valorosa que o talento para os estudos. A existência de uma tradição de disciplina severa na Companhia de Jesus, acabou levando à sofisticação das determinações disciplinares dos colégios jesuíticos. Assim, apoiando-se na dinâmica dos exercícios constantes, dos exames periódicos, da emulação, da premiação e do controle do tempo e do espaço, as normas disciplinares da educação jesuítica se mostraram muito eficientes e contribuiram para a criação de um modelo de ensino que atingiu um sucesso ímpar.

A Ratio Studiorum detém um conjunto de princípios e métodos que lhe conferem singularidade e são pautados em um princípio muito caro a Inácio de Loyola, a saber, o de que o homem é dotado de corpo e alma e que tem uma vida temporal e uma vida espiritual - com ambas merecendo atenção e desenvolvimento.

\subsection{A dinâmica da oração nos Exercícios Espirituais e a dinâmica de estudos na Ratio Studiorum}

Cotejar a dinâmica da oração nos Exercícios Espirituais e a dinâmica de estudos na Ratio Studiorum, revela-se especialmente interessante em virtude de proporcionar a identificação de uma similitude entre ambos; tanto no que diz respeito ao movimento interno como à estrutura. Dessa forma, a partir da leitura dos dois documentos e das considerações de Palaoro (1992), Klein (1997) e Metts (1997), pode-se chegar à proposição de que existe uma relação entre a estrutura básica da oração nos Exercícios Espirituais e os momentos didáticos da Ratio Studiorum. Vale salientar que a expressão Momentos didáticos da Ratio Studiorum, utilizada por Klein (1997), não é encontrada de modo direto e explícito no documento. É um modelo geral proposto pelo autor. Feitas essas considerações, apresenta-se a seguir a Estrutura básica da oração nos Exercícios Espirituais e os Momentos didáticos da Ratio Studiorum, em acordo com os modelos propostos por Klein (1997). 


\section{Estrutura básica da oração nos Exercícios Espirituais}

1. Apresentação dos pontos pelo orientador

2. Oração preparatória

3. Composição do lugar

4. Petição da graça a ser alcançada: objetos

5. Meditação propriamente dita

6. Colóquio com Deu

7. Revisão do período de oração

\section{Momentos didáticos da Ratio Studiorum}
1. Preleção do professor
2. Estudo privado do aluno
3. Exercícios de memória
4. Repetições
5. Trabalhos grupais
6. Exposições
7. Provas e exames

Com efeito, podem ser observadas semelhanças entre a estrutura de ambos os modelos, assim, serão analisados estes pontos separadamente a fim de se investigar efetivamente o quanto, de fato, guardam correspondência entre si. Não se trata de querer igualar os dois documentos, e sim, verificar em que aspectos estruturais os Exercícios Espirituais inspiraram os momentos didáticos da Ratio Studiorum, uma vez que tentar esta transposição direta não parece ser algo razoável.

Acerca dos elementos que compõem a Apresentação dos pontos pelo orientador nos Exercícios Espirituais, Meets (1997) afirma que têm a função principal de preparar o indivíduo para o processo que se iniciará com o foco no conteúdo a ser trabalhado na oração. Do mesmo modo, a Preleção do professor, como passo inicial para o período de estudos concebido pela Ratio Studiorum, é o momento onde a matéria em questão é apresentada de maneira breve e ordenada, com a função de motivar o aluno para depois se pôr em ação no estudo ativo. Segundo Franca (1952, p. 57): “A preleção em sua finalidade é menos informativa do que formativa; não visa comunicar fatos mas desenvolver e ativar o espírito".

Na Ratio é definida uma forma geral de preleção na qual o professor é orientado em quatro pontos básicos. Primeiro: deve, antes de qualquer coisa, preparar-se e estudar repetidas vezes em caráter privado o trecho de que fará a exposição. Segundo: determinase que se faça a opção pela estratégia de explicar em poucas palavras a temática. Terceiro: o professor deve ler cada período do texto em questão e esclarecer os pontos mais obscuros - principalmente se a explicação for em latim, evitar a simples repetição e exprimir aquele pensamento de modo mais inteligível. Quarto: é importante que o professor retome o trecho estudado e faça observações adaptadas às características e necessidades de cada classe (RATIO STUDIORUM, 1952). Já nos Exercícios Espirituais, Inácio de Loyola determina ao orientador que ao serem apresentados os pontos de meditação ou contemplação para o exercitante, deve-se fazê-lo de modo breve ou sumariamente, pois: "[...] assim, a pessoa que contempla, tomando o verdadeiro fundamento da história, reflete e raciocina por si mesma. Encontrando alguma coisa que a esclareça ou a faça sentir mais a história [...]" (INÁCIO DE LOYOLA, 2000, p. 10). Há uma correspondência tanto estrutural como de objetivos entre este ponto da Ratio e dos Exercícios, cabendo tanto ao professor como ao orientador papéis semelhantes: uma exposição inicial curta a fim de aguçar no aluno ou no exercitante o desejo de envolver-se com o tema; criar um ambiente favorável para que o foco recaia sobre o conteúdo a ser trabalhado; e, finalmente, retomando o que foi discutido nesse primeiro momento pedagógico preparar o indivíduo para que em seguida passe a desempenhar um papel ativo no processo.

O segundo momento da dinâmica de oração dos Exercícios é o da Oração preparatória, que é a ocasião em que o exercitante pede graças ao Senhor para que possa 
alcançar seus objetivos. Isso pode parecer irrelevante quando se propõe uma comparação com a dinâmica de estudos da Ratio, entretanto, é importante em virtude de se tratar da ocasião em que acontece a transição para o trabalho ativo do exercitante. Passa-se das diretivas do orientador para o momento em que o indivíduo deve se preparar para efetivamente agir, portanto, a Oração preparatória é uma espécie de preparação pessoal para todo o trabalho por vir. Da mesma forma, o Estudo privado do Aluno, contemplado na Ratio, é o momento em que o estudante dá início ao seu processo individual para só depois dar início aos exercícios propostos. A Preleção dá as diretivas, mas o estudo efetivo deve ser realizado pelo aluno a partir da sua iniciativa pessoal, do mesmo modo como se dá com o exercitante na prática espiritual proposta por Inácio de Loyola (MEETS, 1997). Inácio de Loyola (2000, p. 32) escreve que a Oração preparatória "consiste em pedir graça a Deus nosso Senhor para que todas as minhas intenções, ações e operações sejam puramente ordenadas a serviço e louvor de sua divina Majestade". Ou seja, o indivíduo efetivamente passa a ter um papel ativo no processo e dá início ao seu esforço pessoal e privado para alcançar a sua meta; do mesmo modo como o acadêmico faz em seus estudos. Interessante notar que a Ratio Studiorum determina com precisão desde a distribuição do tempo do estudo - que não deveria exceder duas horas seguidas sem um breve intervalo - até o método como esse estudo deve se desenvolver. A seguinte passagem é bastante ilustrativa neste sentido:

Nas horas marcadas para o estudo privado os que seguem as faculdades superiores releiam em casa os apontamentos da aula, procurando entendêlos e, uma vez entendidos, formulem a si mesmos as dificuldades e as resolvam; o que não conseguirem apontem para perguntar ou disputar (RATIO STUDIORUM, 1952, p.216).

Do mesmo modo os Exercícios determinam tanto o tempo da prática, como por exemplo no trecho: "[...] empregar uma hora em cada um dos cinco exercícios ou contemplações, que se farão a cada dia" (INÁCIO DE LOYOLA, 2000, p. 15), como também propõem, em suas meditações com o auxílio das três potências da alma, a realização de problematizações acerca dos pecados pessoais com o objetivo de entender suas origens e redimir-se. Portanto, pode-se notar que também nesses pontos os Exercícios Espirituais influenciaram a Ratio Studiorum. Tanto por meio da delimitação de horários que "otimizariam" a prática, como também de um modelo de meditação/estudo que em um primeiro momento deveria ser desenvolvido de modo individual, a fim de que o indivíduo pudesse identificar por si mesmo suas falhas.

Já no terceiro momento, a Composição do lugar, tenta-se criar com a utilização da memória e da imaginação uma experiência semelhante à descrita na Preleção e retomada na Oração preparatória. Trata-se de ativar as três potências definidas por Inácio de Loyola - memória, inteligência e vontade - a fim de intensificar a capacidade cognitiva para favorecer a fixação dos conteúdos envolvendo ainda mais o exercitante, buscando preparar-se para a oração propriamente dita. Conforme Inácio de Loyola (2000, p. 32), "a composição consistirá em ver, com os olhos da imaginação, o lugar físico onde se encontra o que quero contemplar". Analogamente, na Ratio Studiorum este é o momento dos Exercícios de memória, ponto em que mentalmente o aluno deve repassar o que aprendeu até a ocasião, buscando também intensificar sua capacidade cognitiva a fim de fixar o conteúdo, para que possa, mais adiante estar apto para as atividades de estudo em grupo (PALAORO, 1992). Caberia aos alunos a constante prática de memorização, que deveria ser testada pelos professores pela solicitação de que fossem recitados trechos completos das lições (RATIO STUDIORUM, 1952). Trata-se - tanto nos Exercícios como na Ratio - 
de envolver ao máximo o indivíduo no processo pedagógico com o emprego de suas faculdades cognitivas, e o objetivo é fazer com que o foco de sua atividade se circunscreva o mais estritamente possível à temática trabalhada.

O quarto ponto da dinâmica de oração dos Exercícios Espirituais é a Petição da graça a ser alcançada, onde os objetivos em razão dos quais está se realizando a oração são retomados, reavivando na mente do exercitante seu propósito (PALAORO, 1992). Este item aparece no momento imediatamente anterior ao da Oração propriamente dita, o que dispõe o indivíduo para o foco desejado, isto após ter sido, nas fases anteriores, mentalmente preparado para chegar à oração devidamente instrumentalizado cognitivamente. Na Ratio Studiorum, este é o ponto das Repetições. Aqui há uma centralização dos conteúdos trabalhados ao longo dos passos anteriores, preparando o indivíduo para que possa se haver bem nas atividades em grupo que são o ápice da dinâmica interna de estudos da Ratio, onde são propostas atividades para os alunos. Na Ratio Studiorum é indicado ao professor que determine aos alunos que realizem repetições tanto na sala de aula quanto em casa. Este processo de repetição é regulamentado da seguinte forma:

Todos os dias, exceto os sábados, os dias feriados e os festivos, designe uma hora de repetição aos nossos escolásticos para que assim se exercitem as inteligências e melhor se esclareçam as dificuldades ocorrentes. Assim um ou dois sejam avisados com antecedência para repetir a lição de memória, mas só por um quarto de hora; em seguida um ou dois reformulem objeções e outros tantos respondam; se ainda sobrar tempo, proponham-se dúvidas. E para que sobre, procure o professor conservar rigorosamente a argumentação em forma [silogística]; e quando nada mais de novo se aduz, corte a argumentação (RATIO STUDIORUM, 1952, p. 146).

Ao final do ano letivo, deveria ocorrer uma repetição geral de todas as lições passadas no período, sendo designado para tal um mês inteiro. Fica evidente com isso a importância dada à repetição na Ratio, sendo utilizada enquanto estratégia pedagógica para fixar o conteúdo. O artifício é amplamente utilizado nos Exercícios Espirituais, onde se pode observar uma especial ênfase no ato de repetir. Há, inclusive, um exercício e duas contemplações dedicadas totalmente à repetição das atividades anteriormente realizadas, a saber, o Terceiro Exercício da Primeira Semana e as Terceira e Quarta Contemplações da Segunda Semana. Determina Inácio de Loyola (2000, p. 38) sobre a repetição: "Prestar atenção e demorar-me mais nos pontos em que senti maior consoloção, desolação ou sentimento espiritual”. Determina a Ratio sobre a repetição: “[...] perguntem-se os pontos mais importantes e mais úteis [...]" (RATIO STUDIORUM, 1952, p. 185). Fica evidente a transposição de um elemento capital dos Exercícios para a proposta de ação educativa da Ratio. A estratégia de repetição não era inédita no âmbito pedagógico, entretanto, pode-se notar que lhe é atribuído um papel central e é mantido o sentido atribuído a ela nos Exercícios (LOPES, 2009). Isto corrobora a hipótese de que há uma estreita relação entre a dinâmica pedagógica empregada pelos jesuítas no campo da espiritualidade e aquela empregada no campo da educação.

Chega-se enfim, nos Exercícios Espirituais, à Oração propriamente dita, que é onde o exercitante utiliza todas as suas faculdades mentais, e algumas vezes os seus sentidos, para meditar ou contemplar os pontos anteriormente selecionados para a oração. No Primeiro Exercício da Primeira Semana, Inácio de Loyola recomenda: "Aplicar a memória ao primeiro pecado [...]. Depois a inteligência, refletindo. Logo, a vontade, querendo 
recordar e compreender tudo isso, para mais sentir vergonha e confusão [...]" (INÁCIO DE LOYOLA, 2000, p.34). Em seguida na Quinta Contemplação da Segunda Semana, escreve que é proveitoso passar os cinco sentidos da imaginação pelos pontos de contemplação (INÁCIO DE LOYOLA, 2000). Trata-se da plenitude do exercício em questão, é aqui que o indivíduo terá sido levado pela estrutura ao máximo de sua capacidade de apreender e experienciar o conteúdo proposto. Na Ratio Studiorum, o quinto ponto da ordem de estudo é o dos Trabalhos grupais, centrados, eminentemente, na dialogia. Trata-se de desafios, disputas e emulações em geral, que, inclusive com o oferecimento de prêmios, dinamicamente levam o indivíduo a experienciar de modo vivo o conteúdo que estuda. Ou seja, há uma dinâmica centrada no exercício, onde são envolvidos tanto aspectos cognitivos como afetivos. Pode-se, inclusive, ler nas Regras do Prefeito da Academia uma determinação explícita para que: "Providencie para que todos os acadêmicos quanto possível, sejam exercitados, por turno, nas várias formas de atividade" (RATIO STUDIORUM, 1952, p. 224). A Ratio Studiorum, como os Exercícios Espirituais, apoiamse no conceito de exercício enquanto elemento fundamental do processo pedagógico. $\mathrm{O}$ indivíduo deve se exercitar a fim de que alcance o objetivo desejado, com seu êxito ou o fracasso repousado sobre sua iniciativa e seu esforço pessoal.

O sexto ponto da dinâmica de oração dos Exercícios é o Colóquio com Deus. Conforme Metts (1997, p. 54): “Considerando tudo que precedeu o colóquio, o exercitante é agora convidado a partilhar o que ocorreu, travando conversa com um amigo". Nos Exercícios, trata-se de um diálogo livre com Deus em que o exercitante pode se certificar, com suas elaborações no diálogo, se de fato apreendeu o que desejava na atividade (PALAORO, 1992). Conforme Inácio de Loyola (2000, p. 35): “O colóquio, propriamente dito, se faz como um amigo fala a seu amigo ou como um servo, a seu senhor, ora implorando um favor, ora acusando-se de uma ação má, ora fazendo confidências e pedindo conselho a esse respeito". Este é o momento das Exposições na Ratio Studiorum, que se trata de apresentações públicas acerca do conteúdo estudado e da experiência dos trabalhos grupais. A este respeito o documento determina que:

Em lugar da lição ordinária designe-se às vezes um aluno que interprete, em forma elegante e desenvolvida, algum dos passos mais importantes da Sagrada Escritura. Terminada a exposição, um ou outro dos condiscípulos poderá formular objeções, que, porém, só deverão ser tiradas dos vários passos da Escritura, dos idiotismos de linguagem ou das interpretações dos SS. Padres (RATIO STUDIORUM, 1952, p. 151).

Trata-se de uma exposição que em seguida pode ser confrontada, o que de alguma maneira remete à ideia do Colóquio enquanto um instrumento valioso no processo de aquisição do conhecimento - tal como proposto por Inácio de Loyola nos Exercícios Espirituais. A realização desta atividade exige do aluno a retomada de tudo o que aprendeu, o que lhe possibilita, do mesmo modo que ao exercitante, ter a dimensão geral de seu aprendizado. Além disso, este ponto auxilia o estudante a acomodar os conteúdos após o processo intenso e agitado que foi o dos Trabalhos grupais.

O último momento da dinâmica da oração nos Exercícios Espirituais é o da Revisão do período de oração, tópico em que o exercitante deve, principalmente, detectar os pontos em que ainda é falho e precisa progredir. Inácio de Loyola determina que este procedimento seja conduzido do seguinte modo:

Terminando o exercício, pelo espaço de um quarto de hora, sentado ou caminhando, examinarei como me saí na contemplação ou meditação. Se 
mal, verei a causa de onde procede, e, quando a descobrir, vou arrepender-me a fim de corrigir-me para o futuro (INÁCIO DE LOYOLA, 2000, p. 44-45).

Considerando esta proposição dos Exercícios, Palaoro (1992, p. 85) escreve que a mesma é importante porque "[...] educa o exercitante, dilatando sua consciência espiritual, aumentando sua transparência, até capacitá-lo a reconhecer com certa maestria os acontecimentos interiores, a distingui-los, compará-los, advertir sua direção”. Trata-se, portanto, de um ponto-chave, uma vez que é onde o indivíduo desenvolve sua capacidade de auto-exame, contribuindo para que melhore sua habilidade de discernimento das situações que o favorecem e o desfavorecem. Na Ratio Studiorum há um elemento correspondente, a saber, as Provas e Exames, onde é avaliado o quanto foi apreendido pelo aluno. Para a realização do exame o seguinte modelo é proposto:

[...] primeiro, leia cada qual uma parte de sua composição, se se julgar conveniente, ordene-se-lhe, em seguida, que corrija os erros, dando a razão de cada um e indicando a regra violada. Aos gramáticos proponhase, depois, a versão imediata para o latim de um trecho vernáculo e a todos se interroguem as regras e outros assuntos estudados nas classes respectivas. Por último, se for necessário, exija-se uma explicação breve de um trecho dos livros explanados em aula (RATIO STUDIORUM, 1952, p. 171).

Além de proporcionar ao professor e à instituição uma medição da aprendizagem, a realização de provas e exames proporciona ao aluno a possibilidade de rever o conteúdo ministrado durante todo o processo de aprendizagem e, em última instância, oferece a ele uma resposta concreta acerca da eficiência de seu estudo, o que lhe dá informações para que possa se emendar nos pontos que se apresentarem falhos. A revisão periódica do que foi aprendido, bem como a elaboração de sínteses durante esse processo - que são características marcantes dos Exercícios e da Ratio -, são elementos que se solidificaram e se tornaram procedimentos chave nas pedagogias Modernas.

\section{Conclusão}

Os Exercícios Espirituais, além de teorizarem de forma marcante, na espiritualidade católica, o papel da disciplina e do trabalho pessoal, delinearam genericamente as bases da pedagogia jesuítica. Ancorar a aprendizagem no trabalho e na disciplina, foi o fundamento para a construção de um estilo pedagógico calcado em regulamentações rígidas e registros minuciosos.

A Companhia de Jesus logrou êxito tanto na esfera religiosa quanto na educativa, contribuindo para que a Igreja Católica se reformasse e se reposicionasse frente ao protestantismo. Com sua ação pastoral, os jesuítas colaboraram para o alargamento do mundo através das missões apostólicas. Já seu novo modo de conceber o homem e seu papel no mundo, concorreu para o desenvolvimento das nações católicas, contribuindo, inclusive, para o progresso científico das mesmas por meio de um modelo educativo que se distinguia por seu rigor e por sua qualidade.

Ao passo destas inovações marcadamente Modernas, os jesuítas não se pretenderam revolucionários. Ajustaram-se às exigências da época, uma vez que as demandas do século XVI pediam por sacerdotes que militassem pela fé católica em vários âmbitos e não fossem somente religiosos honestos para com a Igreja e competentes intelectualmente. Desta 
forma, a dedicação à pastoral educacional deu-se em razão de ter se mostrado objetivamente uma estratégia privilegiada para o fortalecimento da Igreja Católica. A partir desta identificação, Inácio de Loyola encarregou desta atividade os "maiores talentos" da Companhia de Jesus, que em pouco tempo fizeram a educação jesuítica ser reverenciada pela qualidade de seu ensino e de seu quadro docente, bem como pela sua grande expansão e influência.

Com o longo processo de elaboração da Ratio Studiorum, os jesuítas puderam desenvolver um método pedagógico destacado, no qual, as determinações práticas e diretas conduziam os estudos de maneira muito eficiente. Assim, elementos característicos da Ratio como: o foco no indivíduo e no exercício, o estabelecimento de metas, a documentação dos estudos, as repetições, os resumos, as avaliações, a emulação, a premiação e a adaptação de conteúdos tornaram-se bases da pedagogia Moderna. A novidade desta prática consistia em unir, de modo indissolúvel, a espiritualidade ao trabalho. Esta marca Moderna garantiu a eficiência, a coesão e a expansão da Ordem. Vale assinalar que, efetivamente, os principais preceitos da Ratio Studiorum foram questionados de modo contundente apenas a partir do início do século passado.

Com efeito, os jesuítas conduziram um projeto que se destaca tanto no âmbito da religiosidade como no da educação, integrando a estas práticas elementos advindos das demandas da Modernidade que despontava. Ao elaborarem uma pedagogia configurada nos moldes de uma espiritualidade e nela o desenvolvimento do indivíduo, os jesuítas entendiam-na como corolário de uma iniciativa pessoal. Eles também trouxeram para o campo educativo questões referentes ao homem, à sua subjetividade e ao mundo do trabalho. Este fato colaborou para que novas concepções de mundo se articulassem a partir dos elementos trazidos pelos jesuítas para o âmbito educacional. Neste sentido, não é equivocado afirmar que tanto os Exercícios Espirituais como a Ratio Studiorum, já traziam indícios da demanda histórica por um novo tipo de homem, que deveria, de modo mais decisivo nos séculos seguintes, desenvolver seu trabalho em fábricas confinado a um espaço delimitado e submetido a horários rígidos. A vida dos homens começava a ser gerida, principalmente, a partir do controle do espaço e do tempo. Era a Modernidade que se iniciava.

\section{REFERÊNCIAS}

Fontes:

CONSTITUIÇÕES da Companhia de Jesus e NORMAS Complementares. São Paulo: Loyola, 2004.

INÁCIO DE LOYOLA. Carta ao Pe. Antônio Brandão. In: CARDOSO, Armando (Org.). Cartas de Santo Inácio de Loyola. v. 2. São Paulo: Loyola, 1990, p. 82-89.

Carta ao Pe. Diogo Mirão. In: CARDOSO, Armando (Org.). Cartas de Santo Inácio de Loyola. v. 2. São Paulo: Loyola, 1990, p. 100-102.

Carta a Bartolomeu Romano. In: CARDOSO, Armando (Org.). Cartas de Santo Inácio de Loyola. v. 2. São Paulo: Loyola, 1990, p. 135-136.

Exercícios Espirituais. São Paulo: Loyola, 2000. 
RATIO STUDIORUM - Organização e plano de estudos da Companhia de Jesus. In: FRANCA, Leonel (editor). O método pedagógico dos jesuítas: o Ratio Studiorum. Rio de Janeiro: Agir, 1952, p. 119-230.

\section{Literatura de apoio:}

ARNAUT DE TOLEDO, Cézar de Alencar. Instituição da Subjetividade Moderna: a contribuição de Santo Inácio de Loyola e Martinho Lutero. 1996. 168 f. Tese (Doutorado) - Faculdade de Educação, UNICAMP, Campinas, 1996.

ARNAUT DE TOLEDO, Cézar de Alencar; RUCKSTADTER, Flávio Massami M. A filosofia educacional dos jesuítas nas cartas do Pe. José de Anchieta. Acta Scientiarum, Maringá, v. 25, n.2, p. 257-265, 2003.

BERTRÁN-QUERA, Miguel. Introducción histórica y temática. In: LABRADOR, C; DÍEZ ESCANCIANO, A.; BERTRÁN-QUERA, M.; DE LA ESCALERA, J. M. (Orgs.). La Ratio Studiorum de los jesuítas. Madrid: Publicaciones de la Universidade Pontificia Comillas, 1986, p. 15-57.

BOUYER, L. Diccionario de Teología. Trad. Francisco Martinez. Barcelona: Herder, 1983.

CHARMOT, F. La pedagogia de los jesuítas: sus princípios - su actualidad. Madrid: Sapientia, 1952.

DE LETURIA, Pedro. Génesis de los Ejercicios de San Ignácio y su influjo em la fundación de la Compãnia de Jesús (1521-1540). In: Estúdios Ignacianos II: Estudios Espirituales. Roma: Institutum Historicum Societatis Iesu, 1957, p. 3-55.

FRANCA, Leonel. Introdução. In: (editor). $\mathrm{O}$ método pedagógico dos jesuítas: 0 Ratio Studiorum. Rio de Janeiro: Agir, 1952, p. 5-118.

GUILlermoU, Alain. Santo Inácio de Loyola e a Companhia de Jesus. Rio de Janeiro: Agir, 1973.

KLEIN, Luiz Fernando. Atualidade da pedagogia jesuítica. São Paulo: Loyola, 1997.

LACOSTE, Jean-Yves. Dicionário crítico de Teologia. Trad. Paulo Meneses [et al.]. São Paulo: Paulinas: Edições Loyola, 2004.

LOPES, José M. M. Ratio Studiorum: um modelo pedagógico. In: MIRANDA, Margarida (Org.). Código Pedagógico dos Jesuítas: Ratio Studiorum da Companhia de Jesus. Regime escolar e curriculum de estudos. Lisboa: Esfera do Caos, 2009, p. 37-51.

MANACORDA, Mário A. História da Educação: da Antiguidade aos nossos dias. 10. ed. Trad. Gaetano Lo Monaco. São Paulo: Cortez, 2002.

MATEO, Rogelio García. Fuentes filosófico-teológicas de los ejercicios según el currículum académico de su autor. In: PLAZAOLA, Juan. Las fuentes de los ejercicios 
espirituales de San Ignacio: Simpósio Internacional (Loyola, 15-19 Septiembre 1997). Bilbao: Ediciones Mensajero, 1998, p. 467-508.

METTS, Raph E. Inácio sabia: intuições pedagógicas. Trad. Barbara Theoto Lambert. São Paulo: Loyola, 1997.

NAJMANOVICH, Denise. O sujeito encarnado - questões para pesquisa no/do cotidiano. Rio de Janeiro: DP\&A, 2001.

OLIN, John C. Utopia, and the jesuits: essays on the outreach of humanism. New York: Fordham University Press, 1994.

O’MALLEY, John W. Os primeiros jesuítas. Trad. Domingos Armando Donida. São Leopoldo: UNISINOS; Bauru: EDUSC, 2004.

O’NEILL, Charles E.; DOMÍNGUEZ, Joaquín Ma. Diccionario histórico de la Compañía de Jesús: biográfico-temático. Madrid: Publicaciones de la Universidade Pontificia Comillas, 2001. 4 v.

PALAORO, Adroaldo. A experiência espiritual de Sto. Inácio e a dinâmica interna dos exercícios. São Paulo: Loyola, 1992.

PAIVA, José Maria de; PUENTES, Roberto Valdés. A proposta jesuítica de educação: uma leitura das Constituições. Comunicações, Piracicaba, ano 7, n. 2, p. 101-118, nov. 2000

SCHMITZ, Egídio. Os jesuítas e a educação: a filosofia educacional da Companhia de Jesus. São Leopoldo: UNISINOS, 1994.

WEBER, Max. Ensaios de sociologia. Trad. Waltensir Dutra. Rio de Janeiro: Zahar editores, 1963.

Notas:

${ }^{1}$ Professor Doutor do Departamento de Fundamentos da Educação e do Programa de Pós-Graduação em Educação da Universidade Estadual de Maringá. Email: caatoledo@uem.br

${ }^{2}$ Professor Colaborador do Departamento de Teoria e Prática da Educação da Universidade Estadual de Maringá, Mestre em Educação e aluno de doutorado do Programa de Pós-Graduação em Educação da Universidade Estadual de Maringá. Email: jrskalinski@yahoo.com.br.

${ }^{3} \mathrm{O}$ carisma é entendido como uma espécie de força divina conferida a uma Ordem, intimamente vinculada à missão particular a ela atribuída, caracteriza-se como uma função especial e habilidade específica atribuída divinamente aos membros da Ordem no sentido de dispô-los à execução de um ministério. (LACOSTE, 2004). No campo da sociologia, ao desenvolver sua teoria do carisma, Weber (1963) deu uma grande contribuição ao mostrar o quanto o influxo de ideias religiosas pode influenciar no estabelecimento de tipos de poder e de estruturas de domínio, muito notadamente insuflando a emergência de líderes carismáticos.

${ }^{4}$ A mística é o fundamento da vida espiritual das Ordens e tem como seu étimo o vocábulo mistério. É um conceito de origem cristã que pode ser definido como o saber que diz respeito às coisas espirituais e divinas, designando uma experiência com Deus e podendo ser concebida tanto no âmbito individual como coletivo 
Trata-se de algo que se realiza eminentemente no campo da experiência, ou seja, refere-se a uma vivência direta de união com o divino que inspira e motiva para realizações (BOUYER, 1983).

5 Neste trabalho utilizou-se a edição dos Exercícios Espirituais publicada pelas Edições Loyola, cuja tradução para o português foi realizada pelo Centro de Espiritualidade Inaciana de Itaici - a partir do Texto Autógrafo em espanhol.

${ }^{6}$ Neste artigo utilizou-se a tradução para o português da Ratio Studiorum elaborada pelo Pe. Leonel Franca em 1952. Trata-se de uma edição que traz, além do texto completo do documento, uma Introdução na qual é realizado um precioso estudo acerca da Ratio.

${ }^{7}$ Inácio de Loyola (2000, p. 122) oferece a seguinte definição para consolação: "Chamo consolação, quando se produz alguma moção interior, pela qual a pessoa se inflama no amor de seu Criador e Senhor, e, portanto, quando não pode amar em si mesma nenhuma coisa criada na face da terra, exceto no Criador de todas elas".

Recebido em: $\quad 28 / 02 / 11$

Aprovado em: $29 / 04 / 11$ 